\title{
Comparison of Large Eddy Simulations of a convective boundary layer with wind LIDAR measurements
}

\author{
J. G. Pedersen ${ }^{1}$, M. Kelly ${ }^{1}$, S.-E. Gryning ${ }^{1}$, R. Floors ${ }^{1}$, E. Batchvarova ${ }^{1,2}$, and A. Peña ${ }^{1}$ \\ ${ }^{1}$ Department of Wind Energy, Risø Campus, Technical University of Denmark, Roskilde, Denmark \\ ${ }^{2}$ National Institute of Meteorology and Hydrology, Sofia, Bulgaria \\ Correspondence to: J. G. Pedersen (jegp@dtu.dk)
}

Received: 11 January 2012 - Revised: 21 March 2012 - Accepted: 2 April 2012 - Published: 26 April 2012

\begin{abstract}
Vertical profiles of the horizontal wind speed and of the standard deviation of vertical wind speed from Large Eddy Simulations of a convective atmospheric boundary layer are compared to wind LIDAR measurements up to $1400 \mathrm{~m}$. Fair agreement regarding both types of profiles is observed only when the simulated flow is driven by a both time- and height-dependent geostrophic wind and a time-dependent surface heat flux. This underlines the importance of mesoscale effects when the flow above the atmospheric surface layer is simulated with a computational fluid dynamics model.
\end{abstract}

\section{Introduction}

Knowledge about the flow of air in the atmospheric boundary layer (ABL) is an important issue in many areas of society today. These include energy production, pollutant dispersion, transportation and weather forecasting.

Accurate high-resolution observations of the ABL are, however, difficult to obtain. Tower-based measurements usually cover only the atmospheric surface layer (ASL), and are expensive to establish. Radio soundings generally provide a nearly instantaneous profile of the entire ABL, but only infrequently. Modern remote sensing systems such as LIDARs can provide information about the ABL up to a few kilometers at high resolution under favorable conditions (Floors et al., 2011), but the technology is still maturing and the instruments suffer from periods of malfunction and accuracy issues.

These difficulties make computational fluid dynamics (CFD) modeling of the ABL a tempting alternative to field experiments. CFD models allow one to do numerical experiments in a controlled environment and to study the influence of individual physical parameters on the atmospheric flow. For this reason, CFD models have been used for decades in research to simulate surface-layer flows, generally without considering mesoscale meteorological phenomena. Above the ASL however, mesoscale effects become in- creasingly important and should not be neglected (Kumar et al., 2010; Conzemius and Fedorovich, 2010; Gryning et al., 2007; Brown et al., 2006). One important issue is therefore how well CFD models represent the real atmosphere.

In this paper we compare LIDAR measurements with Large Eddy Simulations (LESs) of a daytime/convective ABL. By looking at a specific set of LIDAR measurements from the Danish National Test Station for Wind Turbines, we illustrate how the agreement between observations and LES can depend on mesoscale effects.

The measurements cover a five-hour period on 6 May 2010, during which the ABL was characterized by turbulence generated by both surface stress and buoyancy. Details of the measurements and the numerical model are given in Sect. 2. Results are presented and discussed in Sects. 3 and 4, respectively. Section 5 provides a conclusion of our findings.

\section{Method}

\subsection{Observations}

During the period from the beginning of April 2010 to the end of March 2011, the ongoing tower measurements at the National Test Station for Wind Turbines at Høvsøre, Denmark, were supplemented by LIDAR measurements as part of the Tall Wind project. A pulsed long range wind LIDAR 



Figure 1. Wind speeds from simulations A, B, C and D compared to measurements.

Table 1. Applied forcing in simulations A, B, C and D.

\begin{tabular}{lll}
\hline Simulation & Geostrophic wind & Surface heat flux \\
\hline A & Constant & Constant \\
B & Time dependent & Constant \\
C & Time and height dependent & Constant \\
D & Time and height dependent & Time dependent \\
\hline
\end{tabular}

(WindCube ${ }^{\mathrm{TM}}$ WLS70 by LEOSPHERE) was used to measure the wind speed from a height of $100 \mathrm{~m}$ up to around $2000 \mathrm{~m}$, with a vertical resolution of $50 \mathrm{~m}$; for details see Floors et al. (2011). Measurements with a carrier to noise ratio (CNR) below $-30 \mathrm{~dB}$ are discarded. Sonic and cup anemometers mounted on a meteorological mast provide flux and wind speed measurements from $10 \mathrm{~m}$ above ground level up to $100 \mathrm{~m}$ and $116.5 \mathrm{~m}$, respectively.

The test station is located approximately $2 \mathrm{~km}$ inland from the west coast of Jutland. In this comparison we focus on the period between 08:00 and 13:00 CET on 6 May 2010. During this period it was partly cloudy, and the wind was from the east, varying between 80 and 100 degrees at a height of $10 \mathrm{~m}$. The terrain east of the test station is rural, flat and homogeneous.

\subsection{Model}

LES is one of the most powerful types of CFD modeling available today for studying turbulent flows. With this tech- nique the Navier-Stokes equations are solved explicitly for all fluctuations at scales larger than the effective grid resolution. Smaller eddies and their effects on the flow are parameterized through a subgrid-scale (SGS) model.

We use the NCAR pseudo-spectral LES code descended from Moeng (1984) and Sullivan and Patton (2008), employing the SGS model of Sullivan et al. (1994). The code assumes a dry atmosphere and horizontal homogeneity. The simulated flow is driven by a pressure gradient across the computational domain, specified directly as the geostrophic wind components $U_{\mathrm{g}}$ and $V_{\mathrm{g}}$, and a heat flux imposed at the lower boundary. The turbulent motions are initialized by adding small random perturbations to the initial fields of horizontal wind speed and potential temperature near the surface.

We conducted four different types of simulations (A, B, C and D), trying to reproduce the measured wind profiles. An overview of the simulations is given in Table 1.

All simulations were made in a domain of $6 \mathrm{~km}$ extent in the horizontal directions, and $2 \mathrm{~km}$ in the vertical direction. This corresponds approximately to 6 and 2 times the observed boundary layer height. The domain was covered by 256 grid points in all three directions, giving a resolution of $23 \mathrm{~m}$ in the horizontal directions and $8 \mathrm{~m}$ in the vertical direction. A sensitivity test was carried out by repeating simulation D with $64^{3}, 128^{3}, 256^{3}$ and $512^{3}$ grid points (D1, D2, D3 and D4). The mean wind profiles and the boundary layer growth of simulation D3 and D4 are very similar indicating that $256^{3}$ grid points are sufficient to obtain 


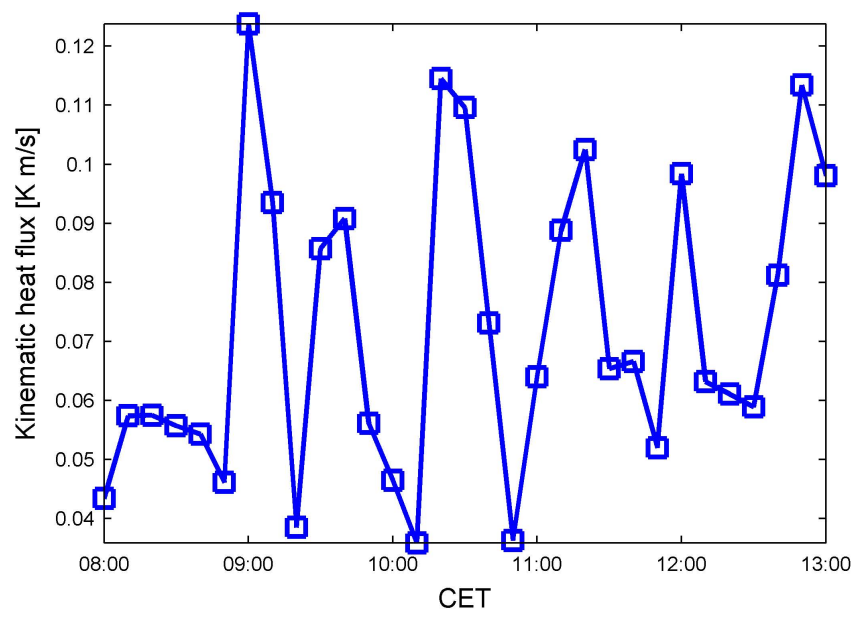

Figure 2. Measured kinematic heat flux at $10 \mathrm{~m}$.

a resolution-independent solution. The number of surfacelayer grid points in simulation D3 and the resulting values of the effective LES Reynolds number and the resolvedto subgrid-stress ratio were furthermore sufficiently high to place the simulation in or near the high accuracy zone as discussed by Brasseur and Wei (2010).

Each simulation ran for $4.5 \mathrm{~h}$ and was initialized at 08:30 CET with a wind speed profile fitted to the mean of the measured profiles between 08:00 and 09:00 CET up to $1000 \mathrm{~m}$. Above this height the initial profile was set to follow the prescribed geostrophic wind. In simulations $A$ and $\mathrm{B}$ the geostrophic wind was specified to be constant with height and was initially set to $6 \mathrm{~m} \mathrm{~s}^{-1}$. In simulations $C$ and D the geostrophic wind was set to decrease linearly with height throughout the domain with a rate of $2 \times 10^{-3} \mathrm{~s}^{-1}$, and in simulations $\mathrm{B}, \mathrm{C}$ and $\mathrm{D}$ the geostrophic wind was furthermore set to increase linearly with time at a rate of $2 \times 10^{-4} \mathrm{~m} \mathrm{~s}^{-2}$ at all heights. The geostrophic wind was updated at the beginning of each time step. The specified time and height dependencies were inferred from the measured wind speed profiles from approximately $1200 \mathrm{~m}$ and above.

The time-dependent surface heat flux in simulation D was updated every $10 \mathrm{~min}$ following the measured kinematic heat flux at $10 \mathrm{~m}$. In $\mathrm{A}, \mathrm{B}$ and $\mathrm{C}$ a constant value of $7.5 \times 10^{-2} \mathrm{~K} \mathrm{~m} \mathrm{~s}^{-1}$ was used. In all the simulations, the initial potential temperature was constant at $280 \mathrm{~K}$ up to $600 \mathrm{~m}$ and then increasing with $3.4 \times 10^{-3} \mathrm{~K} \mathrm{~m}^{-1}$ to the top of the domain.

\section{Results}

Wind speeds from simulations A, B, C and D (Table 1) are compared to measured wind speeds in Fig. 1 ( $\mathrm{a}, \mathrm{b}, \mathrm{c}$ and d). The blue, green and red markers represent hourly averaged wind speeds from the periods 08:00 to 09:00, 10:00 to 11:00 and 12:00 to 13:00 CET. Crosses are LIDAR measurements

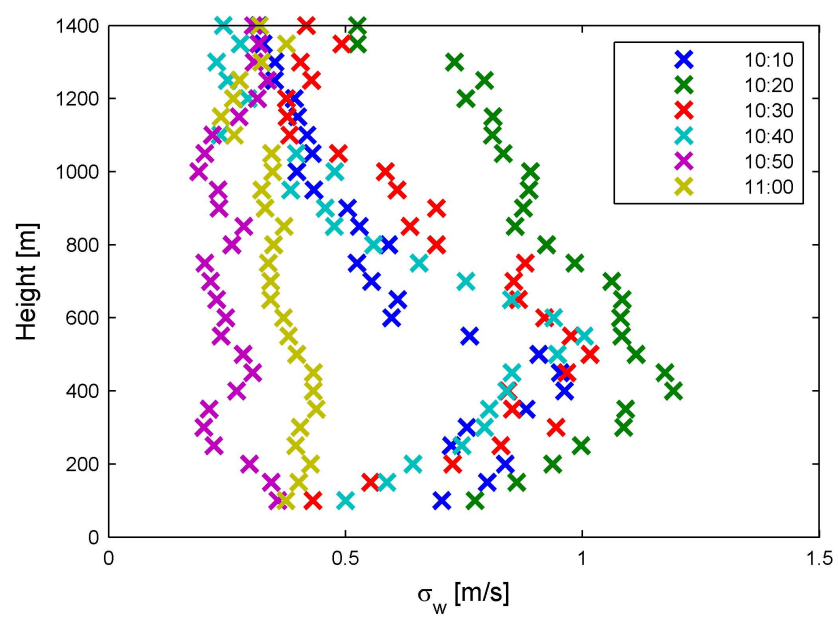

Figure 3. Profiles of $\sigma_{\mathrm{w}}$ measured by the LIDAR.

and triangles are cup anemometer measurements. The solid lines are wind profiles from the simulations. The blue lines are the initial velocity profiles, while the green and the red are hourly averaged profiles between 1.5 and 2.5 and 3.5 and $4.5 \mathrm{~h}$ of simulation time, taken from a position in the middle of the computational domain.

Figure 2 shows the kinematic heat flux measured at $10 \mathrm{~m}$ between 08:00 and 13:00 CET. Figure 3 shows LIDAR profiles of the standard deviation of the vertical wind velocity $\left(\sigma_{\mathrm{w}}\right)$ over $10 \mathrm{~min}$ periods between 10:00 and 11:00 CET. Figure 4 ( $\mathrm{a}$ and $\mathrm{b}$ ) shows corresponding profiles from simulations $\mathrm{C}$ and $\mathrm{D}$.

\section{Discussion}

The mean wind speed profiles of simulation A and B show poor agreement with the measured profiles. The profiles of simulation $\mathrm{C}$ and $\mathrm{D}$ are quite similar and show much better agreement with the measurements. This suggests that in this specific case, the decrease of the geostrophic wind with height and increase with time have a significant impact on the mean wind profiles. The fluctuations of the surface heat flux, on the other hand, seem only to have a small impact.

Regarding the $\sigma_{\mathrm{w}}$-profiles, the varying heat flux has a considerable influence. In both simulations $\mathrm{C}$ and $\mathrm{D}$ the shape of the profiles are quite similar to the measured profiles, but the profiles of simulation D are spread over a wider range of values. This additional scatter gives results more closely resembling the measurements. At high altitudes however, the measured values are generally higher than the simulated values. The fluctuations of the observed heat flux are likely caused by varying cloud cover. In the model we only apply this through the varying surface heat flux in simulation D, but in reality it will also have other effects; for instance the entrainment of air from above the ABL may be influenced. It should be noted that variances measured by LIDAR differ 


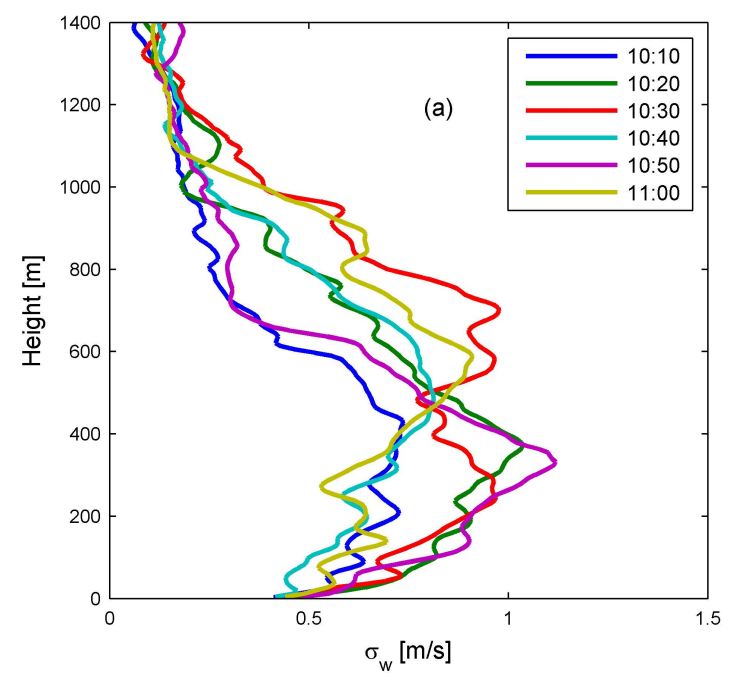

Figure 4. Profiles of $\sigma_{\mathrm{w}}$ from simulation C (a) and D (b).

somewhat from the true variances, as discussed by Sathe et al. (2011). LIDAR measurements of mean wind speeds are generally quite accurate over homogeneous terrain.

\section{Conclusions}

By comparing four different LESs of a convective ABL to a specific set of LIDAR measurements, we have illustrated the importance of considering mesoscale phenomena when using a CFD model to simulate the flow above the ASL. In the specific case studied here, the simulation with a geostrophic wind varying with height and time gave much better agreement with the measured mean wind speed profiles than the simulations where geostrophic wind variations were neglected. Furthermore, we have shown that including fluctuations of the surface heat flux in the CFD model has little effect on the hourly mean wind speed profiles but it improves the prediction of the variability of the $10 \mathrm{~min} \sigma_{\mathrm{w}^{-}}$ profiles.

Acknowledgements. The work is supported by the Danish Research Agency Strategic Research Council (Sagsnr. 2104-08-0025) "Tall wind project" and is related to COST Action ES1002 (WIRE) and the Nordforsk CRAICC project.

Edited by: L. Wald

Reviewed by: A. Boilley and another anonymous referee

The publication of this article is sponsored by the European Meteorological Society.

\section{References}

Brasseur, J. G. and Wei, T.: Designing large-eddy simulation of the turbulent boundary layer to capture law-of-the-wall scaling,

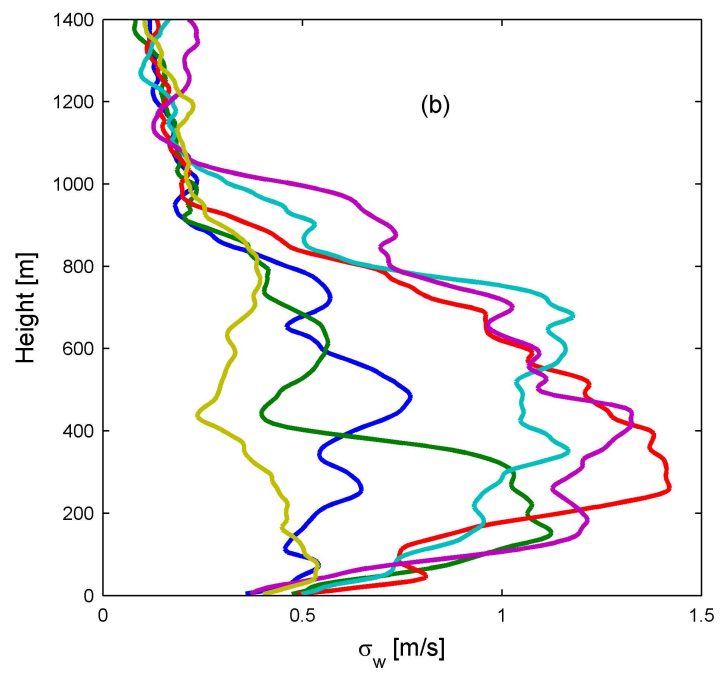

Phys. Fluids., 22, 1-21, 2010.

Brown, A. R., Beljaars, A. C. M., and Hersbach, H.: Errors in parametrizations of convective boundary-layer turbulent momentum mixing, Q. J. Roy. Meteor. Soc., 132, 1859-1876, 2006.

Conzemius, R. and Fedorovich, E.: Large eddy simulation of realistic wind fields in daytime atmospheric boundary layer, in: Proceedings of the 5th International Symposium on Computational Wind Engineering, Chapel Hill, North Carolina, USA, 22-27 May 2010.

Floors, R., Batchvarova, E., Gryning, S.-E., Hahmann, A. N., Peña, A., and Mikkelsen, T.: Atmospheric boundary layer wind profile at a flat coastal site - wind speed lidar measurements and mesoscale modeling results, Adv. Sci. Res., 6, 155-159, doi:10.5194/asr-6-155-2011, 2011.

Gryning, S.-E., Batchvarova, E., Brümmer, B., Jørgensen, H., and Larsen, S.: On the extension of the wind profile over homogeneous terrain beyond the surface boundary layer, Bound.-Lay. Meteorol., 124, 251-268, 2007.

Kumar, V., Svensson, G., Holtslag, A. A. M., Meneveau, C., and Parlange, M. B.: Impact of surface flux formulations and geostrophic forcing on large-eddy simulations of diurnal atmospheric boundary layer flow, J. Appl. Meteorol. Clim., 49, 14961516, 2010.

Moeng, C.-H.: A large-eddy-simulation model for the study of planetary boundary-layer turbulence, J. Atmos. Sci., 41, 20522062, 1984.

Sathe, A., Mann, J., Gottschall, J., and Courtney, M. S.: Can wind lidars measure turbulence?, J. Atmos. Ocean. Tech., 28, 853868,2011

Sullivan, P. P. and Patton, E. G.: A highly parallel algorithm for turbulence simulations in planetary boundary layers: Results with meshes up to $1024^{3}$, 18th Conference on Boundary Layer and Turbulence, Stockholm, Sweden, 2008.

Sullivan, P. P., McWilliams, J. C., and Moeng, C.-H.: A subgridscale model for large-eddy simulation of planetary boundarylayer flows, Bound.-Lay. Meteorol., 71, 247-276, 1994. 